\title{
Early vs late canulation of arteriovenous fistula of hemodialisis - two concepts or trend: east vs west
}

\begin{abstract}
Commencing cannulation of native arteriovenous fistulas in hemodialysis, after its construction, has become a challenge for nurses and nephrologists working in dialysis centers, and there are significant differences in medical practice in this regard. In the following study, we review the literature and the usefulness of ultrasound to help inform these decisions, and we propose a temporary classification for the beginning of the cannulation, after the construction of the native arteriovenous fistulas in hemodialysis, that could be of help for subsequent comparative studies.
\end{abstract}

Keywords: cannulation early, arteriovenous fistula, hemodialysis
Volume 8 Issue I - 2020

\author{
Ignacio Villanueva Bendek \\ Nephrologist, Medical Coordinator Autopista Renal Unit, \\ Colombia
}

\author{
Correspondence: Ignacio Villanueva Bendek, Nephrologist, \\ Medical Coordinator Autopista Renal Unit, Bogotá, Davita, \\ Colombia, Tel 57-3153418121 \\ Email lgnacio.VillanuevaBendek@davita.com
}

Received: December 09, 2019 | Published: January 21, 2020

\section{Introduction}

The native arteriovenous fistula (AVFn) is considered the ideal access to initiate or maintain hemodialysis therapy in patients with end-stage renal failure who initiate this type of treatment, due to its low incidence of complications and its longer duration compared to grafts and catheters. ${ }^{1,2}$ After its surgical construction, it requires a period of time, varying between 2 and 12 weeks, so that the venous path obtains adequate dilation and adequate flow, and can therefore channeled and used in hemodialysis therapy. However, there are differing trends regarding the minimum or optimal time required to consider the AVFn sufficiently mature to initiate cannulation after its construction without risk of infiltration or thrombosis. ${ }^{2,3}$ International guidelines recommend the construction of the AVFn in fourth stage of chronic kidney disease or a period of 3 to 6 months prior to the onset of hemodialysis, the time needed to obtain adequate maturation after construction. Unfortunately, most patients begin hemodialysis treatment without a constructed venous access and instead start with a catheter, exposing themselves to greater comorbidities associated with the use of catheter accesses. ${ }^{4}$

The period of maturation of a vascular access, is defined as the time required from the surgical construction of the AVF to the time to the first cannulation of the AVF, to minimize risk of complications from the cannulation procedure. Although the optimal timing for the onset of cannulation of the constructed AVF is a controversial issue, studies suggest that early cannulation (before two weeks) can cause complications that significantly reduce the survival of the AVF. It is, therefore, critical to determine the ideal time to start cannulation of the AVF. ${ }^{5}$ The art of a good cannulation of the native fistula requires the proper insertion of the needle, and this requires not only a high level of skill on behalf of the nursing staff, but also a knowledge the science of fistula maturation. ${ }^{6}$ There are marked geographical differences in practice to initiate the first cannulation after the construction of the AVFn between East (Japan) and West (Europe and United States) according to a recent DOPPS study - Figure 1.

While in Japan the recommend time period for cannulation of native fistulas is 10 days after construction, in the West (Europe and the United States) the practice is to cannulate on average after 46 and 82 days after construction. This is a significant difference, and carries potential risks such as exposure to infections, related to prolonged use of the hemodialysis catheter. ${ }^{7,8}$ These marked differences between these regions of the world can be explained for several reasons according to Michael Allon ${ }^{7}$ racial characteristics of patients, surgical training, nursing staff and hemodialysis prescription; a lower response to vasodilation and blood flow mediated by nitric oxide is observed in African-American patients compared to other races, a population not as largely present in Japan; greater surgical training for surgeons in Japan and Europe compared to those in the United States; a lower workload for dialysis nurses in Japan allowing greater dedication at the time of cannulation; and finally patients in Japan are relatively smaller in size and dialysis sessions are longer ( 5 hours) and have a lower dialysis blood flow ( $200 \mathrm{ml} / \mathrm{min}$ ), allowing the administration of adequate dialysis, even with a relatively small AVFn. In contrast, patients in the United States are heavier, with shorter dialysis sessions, so they require a larger AVFn, which requires a much greater dialysis blood flow to provide adequate dialysis.

Although there is no exact criterion that defines the moment of maturation of the AVFn, there are clinical criteria used frequently in practice. These include the identification of a visible, palpable vein with a minimum length of $8-10 \mathrm{~cm}$, a sufficient diameter, and a good, palpable trill, as well as a minimum construction time varying between 4 and 10 weeks. These are considered good indicators that the AVFn will allow a cannulation with two needles and will support a good flow for adequate dialysis (Figure 1). ${ }^{4}$ Doppler ultrasound is a non-invasive procedure, which has been used for many years in many fields of nephrology, among other things, to help determine the maturation of the fistula and / or to facilitate the location of the venous path when it is not visible. ${ }^{9}$

One of the greatest uses of ultrasound is the confirmation of the maturation of native AV. ${ }^{10}$ Prolonged waiting times for cannulation or doubts about the viability of the fistula are not uncommon in clinical practice. Therefore, in the event that the physical examination generates doubts regarding the maturation of the fistula, an ultrasound examination, considered proof of choice, can be performed. A diameter of $4 \mathrm{~mm}$ with a flow of $500 \mathrm{ml}$ has been established as maturation criteria by some studies. ${ }^{11}$

Other clinical guidelines consider an ideal AV fistula one that meets the "6" rule: no more than $6 \mathrm{~mm}$ deep, at least $6 \mathrm{~mm}$ in diameter, and with a minimum flow of $600 \mathrm{ml} / \mathrm{min}$ Figure $2 .{ }^{4}$ Maturation of nonassisted AVF is predicted by blood flow, location, depth, and stenosis of the AVF. ${ }^{12}$ However, the postoperative diameter of the venous 
path of the AVF has the highest predictive index of greater long-term posterior permeability Figure 3.13

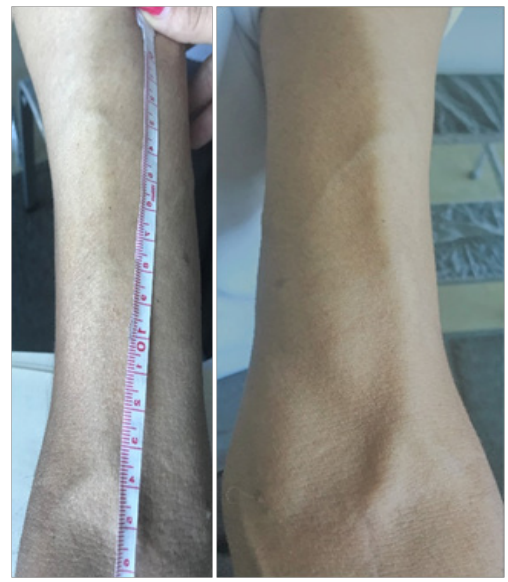

Figure I AVFn cephalic radius 2 I-day-old, with visible venous path of $>8 \mathrm{~cm}$ for cannulation (With patient authorization).

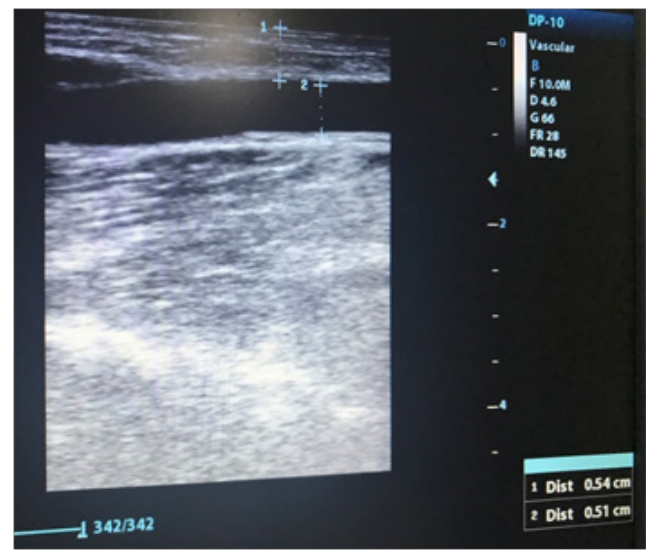

Figure 2 Native arteriovenous fistula, ultrasound measurements $0.54 \mathrm{~mm}$ depth and diameter: $0.51 \mathrm{~mm}$.

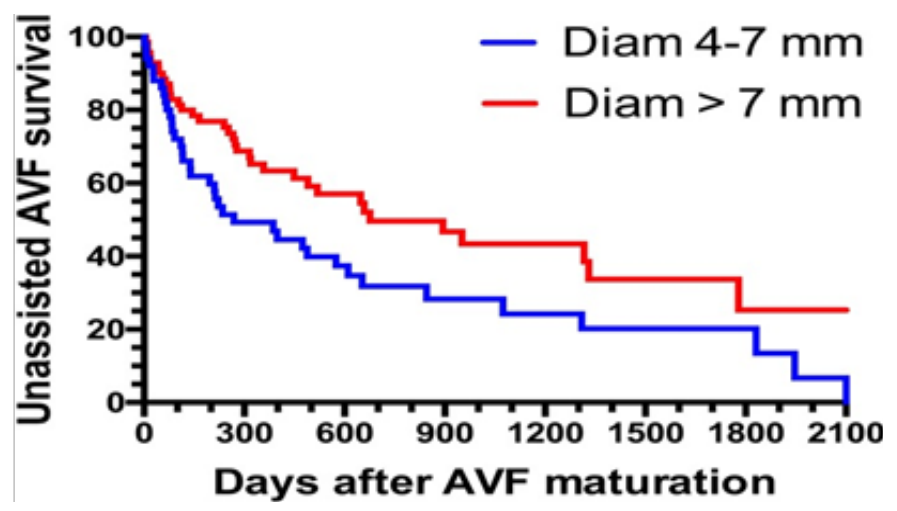

Figure 3 Postoperative diameter of the venous path of the AVF has the highest predictive index of greater long-term posterior permeability.

In some countries there are guidelines and policies with incentives for providers to promote fistulas to their patients, and they have become quality indicators to evaluate dialysis centers. ${ }^{14,15}$ However, the supposed benefits of fistulas are not achieved unless vascular access properly matures. ${ }^{16}$ It should be borne in mind that clinical maturation is a dynamic process in which vascular remodeling is facilitated by nitrous oxide release and elastin decomposition to allow enlargement of the draining vein. ${ }^{6}$

Table I International differences in arteriovenous accesses for hemodialysis

\begin{tabular}{lc}
\hline Time to first successful AVF USE & $\mathbf{2 0 0 9 - 2 0 ~ I 5 ~}$ \\
\hline Japan & 10 Days \\
Europe /New Zealand & 46 Days \\
United States & 82 Days
\end{tabular}

Early cannulation (before three or four weeks, after its construction), is not without risks. Infiltration, thrombosis and loss of access, will not only constitute a loss of time and investment in the construction of access, especially in countries where resources for health are limited, ${ }^{5}$ but more importantly may negatively affect the perception of the patient regarding a new reconstruction procedure. ${ }^{17}$ Despite these risks, the benefit of early cannulation is a decreased amount of time with a catheter, meaning less time a patient is exposed to the risk of associated infections and a lower risk of thrombosis of the venous access when removing the catheter. Reviewing the practice in Japan, where FAVn are cannulated 10 days after construction, as well as DOPPS studies, ${ }^{7,8}$ we suggest a classification for cannulation of the FAVn after construction:

\begin{tabular}{ll}
\hline Classification & Time of first cannulation \\
\hline Premature Cannulation & Before I4 days (2 weeks) \\
Early Cannulation & Between I5 and 28 days (2 and 4 weeks) \\
Late Cannulation & After 28 days (after 4 weeks) \\
\hline
\end{tabular}

This classification is based exclusively on time, and does not take into consideration erroneous or inappropriate behavior of the different dialysis centers,. This classification could be used as a base from which to carry out different comparative and prospective studies to assess the safety of cannulation according to the time.

\section{Conclusion}

Based on various published studies, observable, clinical criteria of the nursing staff, such as adequate trill and / or superficial venous dilation, and the use of ultrasound criteria (such as a diameter $>4 \mathrm{~mm}$ ), it can be said that there are good predictors of the maturation of a FAVn. This practice could therefore allow for successful, early cannulation in select cases, avoiding a catheter implant or the prolongation of catheter use. The experience and skills of nursing staff are vital in this regard. Research is required to identify predictive and clinically useful factors in order to guarantee a successful cannulation of the fistula, as well as to understand the pathophysiology of its maturation. In this sense, randomized clinical trials would be ideal methods to compare the effect of early versus delayed cannulation on the survival of the vascular access.

\section{Acknowledgments}

To the nursing staff of the Renal Unit Davita Autopista Bogotá, and Caroline Knudsen for its grammatical support.

\section{Funding details}

None. 


\section{Conflicts of interest}

The author declares there is no conflict of interest.

\section{References}

1. Charmaine E Lok, Robert Foley. Vascular Access Morbidity and Mortality: Trends of the Last Decade. Clin J Am Soc Nephrol. 2013;8(7):1213-1219.

2. Pisoni RL, Arrington CJ, Albert JM, et al. Facility Hemodialysis Vascular Access Use and Mortality in Countries Participating in DOPPS: An Instrumental Variable Analysis. Am J Kidney Dis. 2009;53(3):475-491

3. Pisoni RL, Zepel L, Fluck R, et al. International Differences in the Location and Use of Arteriovenous Accesses Created for Hemodialysis: Results From the Dialysis Outcomes and Practice Patterns Study (DOPPS). Am J Kidney Dis. 2018;71(4):469-478.

4. National Kidney Foundation. KDOQI clinical practice guidelines and clinical practice recommendations for vascular access 2006. Am J Kidney Dis. 2006;48(Supple 1):S176-S322.

5. Rajiv Saran, Dawn M Dykstra, Ronald L Pisoni, et al. Timing of first cannulation and vascular access failure in haemodialysis: an analysis of practice patterns at dialysis facilities in the DOPPS. Nephrology Dialysis Transplantation. 2004;19(9):2334-2340.

6. Matthew J Oliver. The Science of Fistula Maturation. J Am Soc Nephrol. 2018;29(11):2607-2609.

7. Michael Allon. Lessons from International Differences in Vascular Access Practices and Outcomes. AJKD. 2018;71(4):452-454.

8. Kukita K, Ohira S, Amano I, et al. 2011 update Japanese Society for Dialysis Therapy Guidelines of Vascular Access Construction and Repair for Chronic Hemodialysis. Ther Apher Dial. 2015;19(Suppl 1):1-39.
9. Villanueva Bendek I, Ruiz M. Uso de ultrasonido en fístulas arteriovenosas de difícil canulación en hemodiálisis. Revista Colombiana De Nefrología. 2019;6(1):48-56.

10. José Ibeas-López, Joaquim Vallespín-Aguado. Ecografía del acceso vascular para hemodiálisis: conceptos teóricos y prácticos. Criterios. Nefrologia Sup Ext. 2012;3(6):21-35.

11. Robbin M L, Chamberlain N E, Lockhart ME, et al. Hemodialysis Arteriovenous Fistula Maturity: US Evaluation. Radiology. 2002;225(1):59-64.

12. Robbin ML, Greene T, Allon M, et al. Prediction of Arteriovenous Fistula Clinical Maturation from Postoperative Ultrasound Measurements: Findings from the Hemodialysis Fistula Maturation Study. J Am Soc Nephrol. 2018;29(11):2735-2744.

13. Crystal A Farrington, Michelle L Robbin, Lee T, et al. Postoperative Ultrasound, Unassisted Maturation, and Subsequent Primary Patency of Arteriovenous Fistulas. Clin J Am Soc Nephrol. 2018;13(9):1364-1372.

14. Allon M, Dinwiddle L, Lacson E Jr, et al. Medicare reimbursement policies and hemodialysis vascular access outcomes: a need for change. J Am Soc Nephrol. 2011;22(3):426-30.

15. Chester A Amedia Jr, Bolton WK, Cordray T, et al. Vascular access for HD: A ligning payment with quality. Semin Dial. 2011;24(1):37-40.

16. Vachharajani TJ. The Role of Cannulation and Fistula Care. Seminars in Dialysis. 2015;28:24-27.

17. $\mathrm{Xi}$ W, Harwood L, Diamant MJ, et al Patient attitudes towards the arteriovenous fistula: a qualitative study on vascular access decision making. Nephrol Dial Transplant. 2011;26(10):3302-3308. 